\title{
Impact of fractional order over time response for DC-DC converters with fractional capacitors
}

\author{
Impacto del orden fraccional sobre la respuesta en el tiempo de convertidores DC- \\ DC con capacitores fraccionales
}

\author{
D. E. Betancur-Herrera ; N. Muñoz-Galeano iD ; J. B. Cano-Quintero iD ; J. M. López-Lezama iD
}

\begin{abstract}
This paper analyses the impact of fractional orders of derivatives over the response of DC-DC converters which includes fractional capacitors and their parasitic losses for a more realistic approximation of the converter. A fractional model is proposed and is applied for a Boost DC-DC with a fractional capacitor in its DC bus. The fractional model is obtained using Kirchhoff laws and applying the conventional switching model. Then, the resulting set of fractional differential equations is in the Caputo's sense and was solved using Wavelets method. Solutions were appropriately shown using 3D representations, varying the duty cycle and the fractional order to determine the behavior of the fractional capacitor voltage, inductor current and output voltage. Ripples and steady state values were determined. Results show high dependence of the fractional order in the variables related to the voltage in the fractional capacitor. With respect to the current, results show that the fractional order does not significantly affect its steady state and ripple.
\end{abstract}

Index Terms - Caputo's equations, DC-DC converters, fractional capacitor, fractional differential equations, wavelet method.

Resumen-Este artículo analiza el impacto de los órdenes fraccionales de las derivadas sobre la respuesta de los convertidores DC-DC que incluye capacitores fraccionales y sus pérdidas parásitas para una aproximación más realista del convertidor. Se propone un modelo fraccional y se aplica para un convertidor Boost DC-DC con un condensador fraccional en su bus DC. El modelo fraccional se obtiene utilizando las leyes de Kirchhoff y aplicando el modelo de conmutación convencional. Posteriormente, el conjunto resultante de ecuaciones diferenciales fraccionales está en el sentido de Caputo y es solucionado usando el método Wavelet. Las soluciones se mostraron apropiadamente usando representaciones 3D,

This manuscript was sent on January 21, 2020 and accepted on June 10, 2020. This work was supported by the Colombia Scientific Program within the framework of the call Ecoistema Científico (Contract No FP44842-2182018).

David E. Betancur-Herrera is with the Department of Electrical Engineering, Universidad de Antioquia (UdeA), Calle 67 No 53-108, Medellín, Colombia (e-mail: desteban.betancur@udea.edu.co).

Nicolás Muñoz-Galeano is with the Department of Electrical Engineering, Universidad de Antioquia (UdeA), Calle 67 No 53-108, Medellín, Colombia (e-mail: nicolas.munoz@udea.edu.co).

Juan B. Cano-Quintero is with the Department of Electrical Engineering, Universidad de Antioquia (UdeA), Calle 67 No 53-108, Medellín, Colombia (e-mail: bernardo.cano@udea.edu.co).

Jesús M. López-Lezama is with the Department of Electrical Engineering, Universidad de Antioquia (UdeA), Calle 67 No 53-108, Medellín, Colombia (e-mail: jmaria.lopez@udea.edu.co). variando el ciclo de trabajo y el orden fraccional para determinar el comportamiento del voltaje fraccional del capacitor, la corriente del inductor y el voltaje de salida. Se determinaron las ondas y los valores de estado estacionario. Los resultados muestran una alta dependencia del orden fraccional en las variables relacionadas con el voltaje en el condensador fraccional. Con respecto a la corriente, los resultados muestran que el orden fraccional no afecta significativamente su estado estable y ondulación.

Palabras claves- Capacitores fraccionales, ecuaciones diferenciales fraccionales, ecuaciones de Caputo, convertidores DC-DC.

\section{INTRODUCTION}

WEW developments in several fields of science and 1 engineering allow building many circuital devices such as capacitors and inductors with fractional characteristics [1]. These devices (known as fractional devices) are carrying to a new revolution in engineering; for example, the invention of ultracapacitors has become an important milestone in the field of energy storage devices [1], [2]. Ultracapacitors (or fractional capacitors from the mathematical perspective) have been used in DC-DC converters in which the most promising applications are: 1) hybrid electric vehicles, 2) traction and transport systems, 3) energy quality, 4) micro grids, and 5) energy provision and support [3]-[5]. In this sense, it is of paramount importance to understand the behaviour of DC-DC converters with fractional capacitors.

During the last years, some works were focused on modelling DC-DC converters with fractional devices [1], [6], [7]; these works modelled the dynamic of DC-DC converter with fractional inductors and capacitors, nevertheless parasitic losses were not considered. Our paper presents an analysis that includes the model of real DC-DC converters with fractional capacitors and takes a numerical method [1] to solving the resultant fractional differential equations system. In this way is possible to avoid the use of circuit approximations to model the fractional capacitor.

The fractional model was deduced for a Boost converter where parasitic losses were modelled through series resistances in the inductor and the fractional capacitor. A set of FDE was obtained by using Kirchhoff laws and following the methodology reported in [11]. The resulting set of FDE are 
in the Caputo's sense [10], [12]. Caputo's derivatives appropriately relate voltages and currents in fractional devices. Finally, Wavelets method was implemented to solve the FDE set [13].

The impact of the fractional order $\alpha$ over real DC-DC converters has not been reported in the technical literature yet. So that, the purpose of this paper is to report such impact, showing how the fractional order $\alpha$ modifies the dynamic of real DC-DC converters. The analysis includes the behaviour of voltage and current ripples and steady state analysis for both fractional capacitor voltage and inductor current.

This paper is organized as follows: Section 2 presents some basic definitions regarding FDE which allow a better understanding of the paper. Section 3 presents a discussion on the solution approach of FDE. Section 4 includes a solution for the FDE [13]. Finally, conclusions are presented in Section 5.

\section{BASIC DEFINITIONS}

Some basic definitions are presented in this section for a better understanding of the proposed model.

\section{A. Additional requirements grammar function}

Gamma Function $\Gamma(z)$ is defined by (1).

$$
\Gamma(z)=\int_{0}^{\infty} t^{z-1} e^{-t} d t
$$

Where the real part of the complex variable $z, \operatorname{Re}(z)>0$ and $t>0$. The Gamma Function is a generalization of the factorial function from integer to complex variables [12]. Using the definition of the Gamma Function, it is possible to prove that $\Gamma(z)$ exists for all $z$ except $\operatorname{Re}(z)<0$.

\section{B. Integral of Riemann-Liouville}

The definition of Riemann-Liouville's integral for a function $f(x)$ is given by (2) [15]. In this case, $\tau$ represents the integration variable, $f(x)$ corresponds to the function under fractional integration and $\alpha$ is the fractional order of the Riemann-Liuoville integral.

$$
I^{v} f(x)=\frac{1}{\Gamma(v)} \int_{a}^{x}(x-\tau)^{v-1} f(\tau) d \tau
$$

\section{Fractional Derivative of Caputo}

The definition of Caputo's fractional derivative $\left({ }^{c} D^{v} f(x)\right)$ is given by (3) [14], [15].

$$
{ }^{c} D^{v} f(x)=\frac{1}{\Gamma(\alpha)} \int_{a}^{x}(x-\tau)^{\alpha-1} f^{n}(\tau) d \tau
$$

Where $\alpha=n-v \geq 0$ and $v$ corresponds to the order of the derivative in the interval $n-1 \leq v<n, n$ is an integer number and $x>a$. Equation (3) is applied to functions with continuous $n$-derivatives and derivable in the interval $[a, x)$ so that $\int_{a}^{x} f(x) d x<\infty$; in this sense, (3) is unique in the interval $[a, x)$. In the limit $v \rightarrow n$, (3) is reduced to a n-order integer derivative.

\section{Fractional Differential Equation}

A linear fractional differential equation can be defined as follows:

$$
\begin{aligned}
a_{n}(x){ }^{c} D^{v_{n}} f(x) & +\cdots+a_{1}(x){ }^{c} D^{v_{1}} f(x) \\
& +a_{0}(x) f(x)=k
\end{aligned}
$$

Where $a_{n}, \ldots, a_{0}$ and $k$ are real constants, some or all derivatives are in the Caputo's sense and some derivatives might be ordinary derivatives.

\section{E. Model of Fractional Capacitor}

The model of fractional capacitors is based on fractional derivatives in the sense of Caputo. This model follows the trend of modern science to use recent mathematics theories for modelling some physical phenomena, this has the advantage to collect the voltage, capacitance and current in the same expression. This model corresponds to the model presented in [10], [12] which is described as follows:

$$
i_{c}(t)=C{ }^{c} D^{\alpha} v_{c}(t)
$$

Where $0<\alpha \leq 1$, the derivative in (5) is defined as a fractional derivative of Caputo [12]. The values of the fractional order $\alpha$ change in function of switching frequency, where $\alpha$ increases with the switching frequency [10]. Typical values of $\alpha$ are presented in [16].

\section{BOOST CONVERTER Fractional MODEL}

A real Boost converter with a fractional capacitor $C$ is shown in Fig. 1. It is supposed that the effect of loses in the fractional capacitor and inductor are equivalent to the effect of the resistors $R_{C}$ and $R_{L}$, respectively. Applying Kirchhoff laws in each switching state and the methodology reported in [9], equations (6) and (7) are obtained, which model the voltage of the fractional capacitor $\left(v_{c}\right)$ and the current in the inductor $\left(i_{L}\right)$. Where $\phi_{C}=\frac{R_{C}}{1+\alpha_{C}}$ and $\alpha_{C}=\frac{R_{C}}{R}$.

$$
\begin{gathered}
L \frac{d i_{L}(t)}{d t}=v_{g}-\left(R_{L}+\phi_{C}(1-\mu)^{2}\right) i_{L}+\left(\frac{\phi_{C}}{R}-1\right)(1 \\
-\mu) v_{C} \\
C^{c} D^{\alpha} v_{c}(t)=\frac{1}{\left(1+\alpha_{C}\right)}\left((1-\mu) i_{L}-\frac{v_{C}}{R}\right)
\end{gathered}
$$




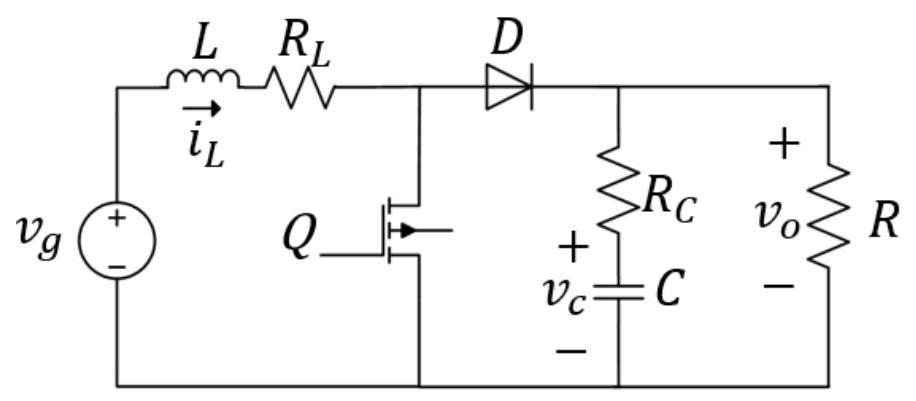

Fig. 1. Boost converter with a fractional capacitor.

Where $\mu$ is a binary variable which is 0 when $Q$ is open and 1 when $Q$ is closed. Note that equations (6) and (7) are similar to those obtained for the Boost converter when the capacitor is modelled with ordinary differential equations. The dynamic of the Boost converter is simple when the order of the derivatives in (6) and (7) are integer; however, with a fractional order, the dynamic changes in function of the fractional order of the derivative $\alpha[10]$.

\section{Solution OF Boost CONVERTER Fractional Model}

The aim of this section is to show the solution of (8) and (9) and illustrate the behaviour of a more realistic Boost DC-DC converter in function of the fractional order $\alpha$ and Duty (D) (6), (7). The following parameters were considered: $\mathrm{L}=$ $40 \mathrm{mH}, \mathrm{C}=10 \mathrm{mF}, \mathrm{R}=10 \Omega, \mathrm{vg}=10 \mathrm{~V}, R_{L}=0.5$ and $R_{c}=0.5$ [11]. Fractional order $(\alpha)$ of derivatives are limited in the interval $0<\alpha<1$ [1], $\alpha$ is limited in this interval in concordance to definition of first order Caputo's fractional derivative and relation (5) provided by [12]. The fractional model of this converter is as follows:

$$
\begin{gathered}
\begin{aligned}
40 \times 10^{-3} \frac{d i_{L}(t)}{d t}=10-\left(0.5+0.4761(1-\mu)^{2}\right) i_{L} \\
+(0.0746-1)(1-\mu) v_{C} \\
10 \times 10^{-3}{ }^{c} D^{\alpha} v_{C}(t)=0.9523\left((1-\mu) i_{L}-\frac{v_{C}}{10}\right)
\end{aligned}
\end{gathered}
$$

The solution of (8) and (9) is presented for a fractional order $\alpha$ which varies between 0.7 to 0.995 using wavelets method [13].

Two basic characteristics of time response for the Boost converter analysed, namely: ripple and steady state value.These characteristics are applied over the current through the inductor $i_{L}$ and the voltage of the ultracapacitor $v_{c}$.

Fig. 2 shows the voltage ripple of the fractional capacitor which has a clear tendency to increase when both $\alpha$ and duty decrease. High values of voltage ripple are not convenient since they cause poor voltage regulation. Then; if $\alpha$ is near 0.7 or less, duty must to be restricted to high values for an appropriate operation, it could be more than 0.6 according to the limits established by the designer.

Fig. 3 shows the current ripple of the inductor which decreases when the duty is increased; however, it remains almost constant when $\alpha$ is increased. So, it can be stated that current ripple does not depend on $\alpha$ for most cases. Relation between duty and current ripple is linear as expected when the fractional order is not considered; nevertheless, for values of duty lower than 0.55 and for low values of $\alpha$ (lower than 0.7 ), the current ripple tends to be attenuated.

Steady state voltage for the fractional capacitor is shown in Fig. 4. Note that the steady state voltage does not present significant changes for fractional orders higher than 0.7. On the other hand, the steady state voltage has a strongly dependence on duty as expected when the fractional order is not considered, decreasing when duty is increased and approaching zero when duty approaches one. For lower values of $\alpha$, the maximum value of steady state voltage tends to be moved to the right on the duty axis.

Fig. 5 shows a clearly dependence of the steady state current value; when the fractional order is increased, the current slightly increases. As regards the duty cycle dependence, steady state current decreases when duty increases. 


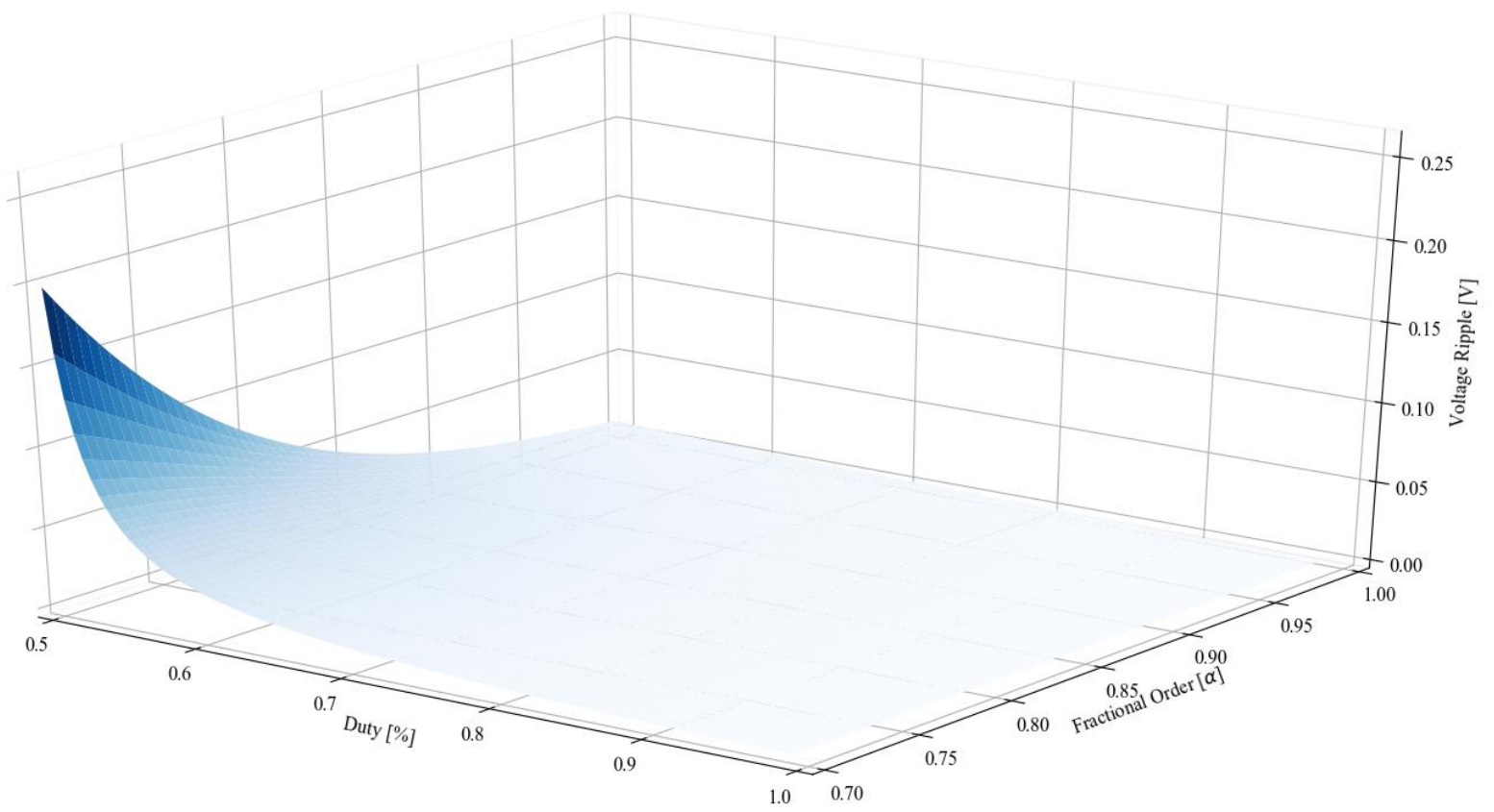

Fig. 2. Ripple for the voltage in the fractional capacitor for $0.7<\boldsymbol{\alpha}<\mathbf{1}$ and $\mathbf{0 . 5}<\boldsymbol{D}<\mathbf{1}$.

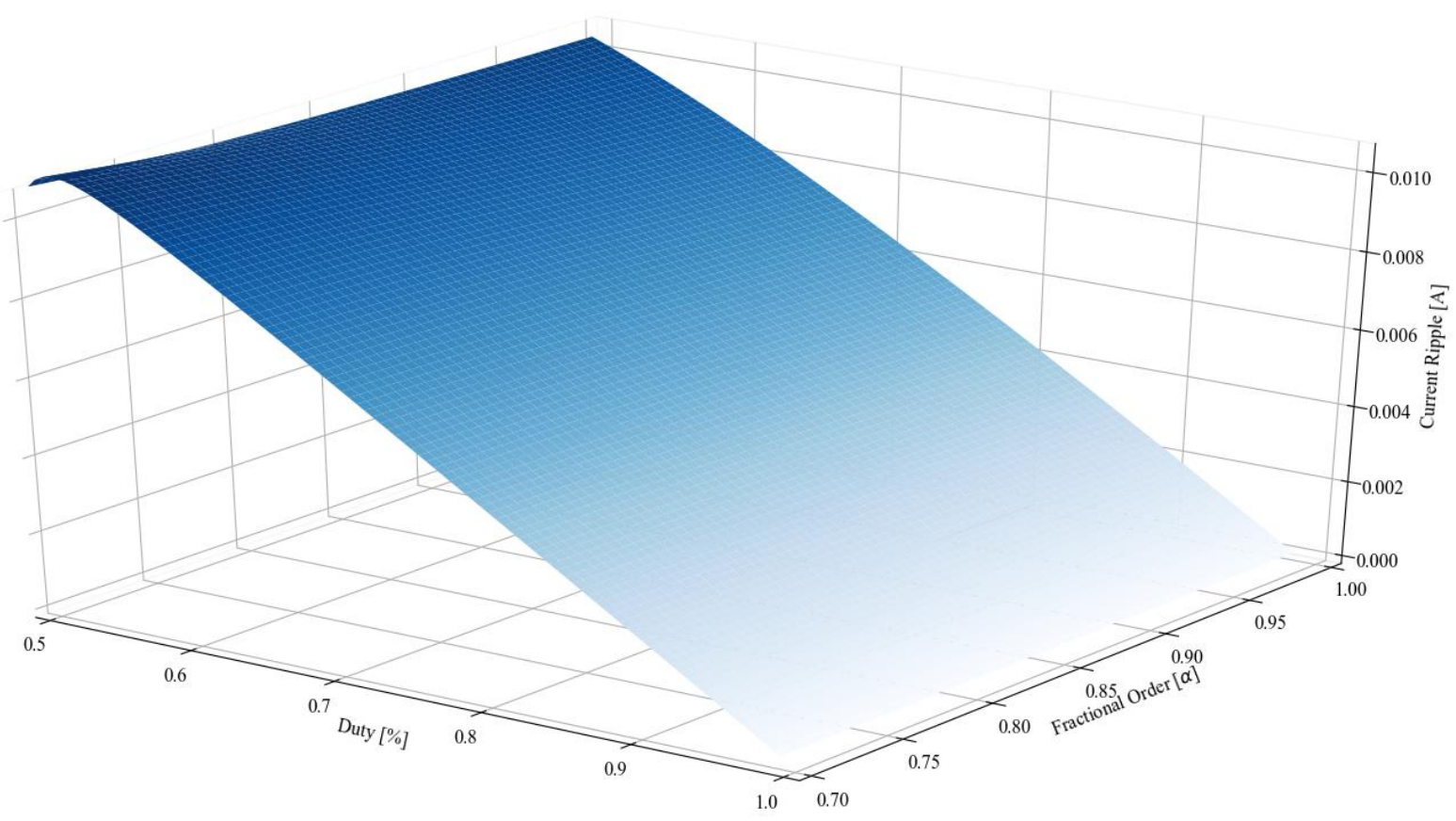

Fig. 3. Ripple for the current through the inductor $0.7<\boldsymbol{\alpha}<\mathbf{1}$ and $\mathbf{0 . 5}<\boldsymbol{D}<\mathbf{1}$. 


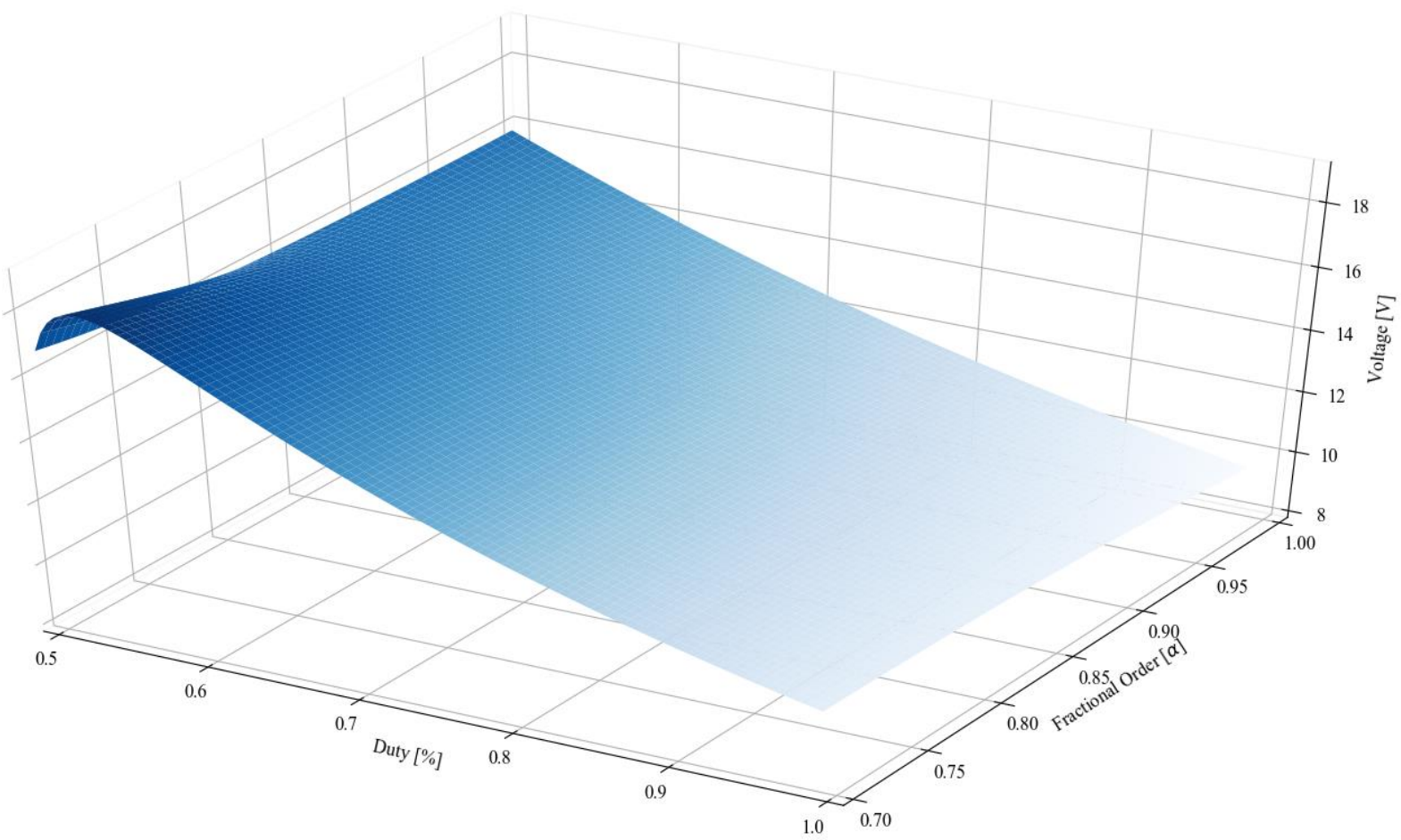

Fig. 4. Steady state for the voltage in the fractional capacitor for $0.7<\alpha<1$ and $0.5<D<1$.

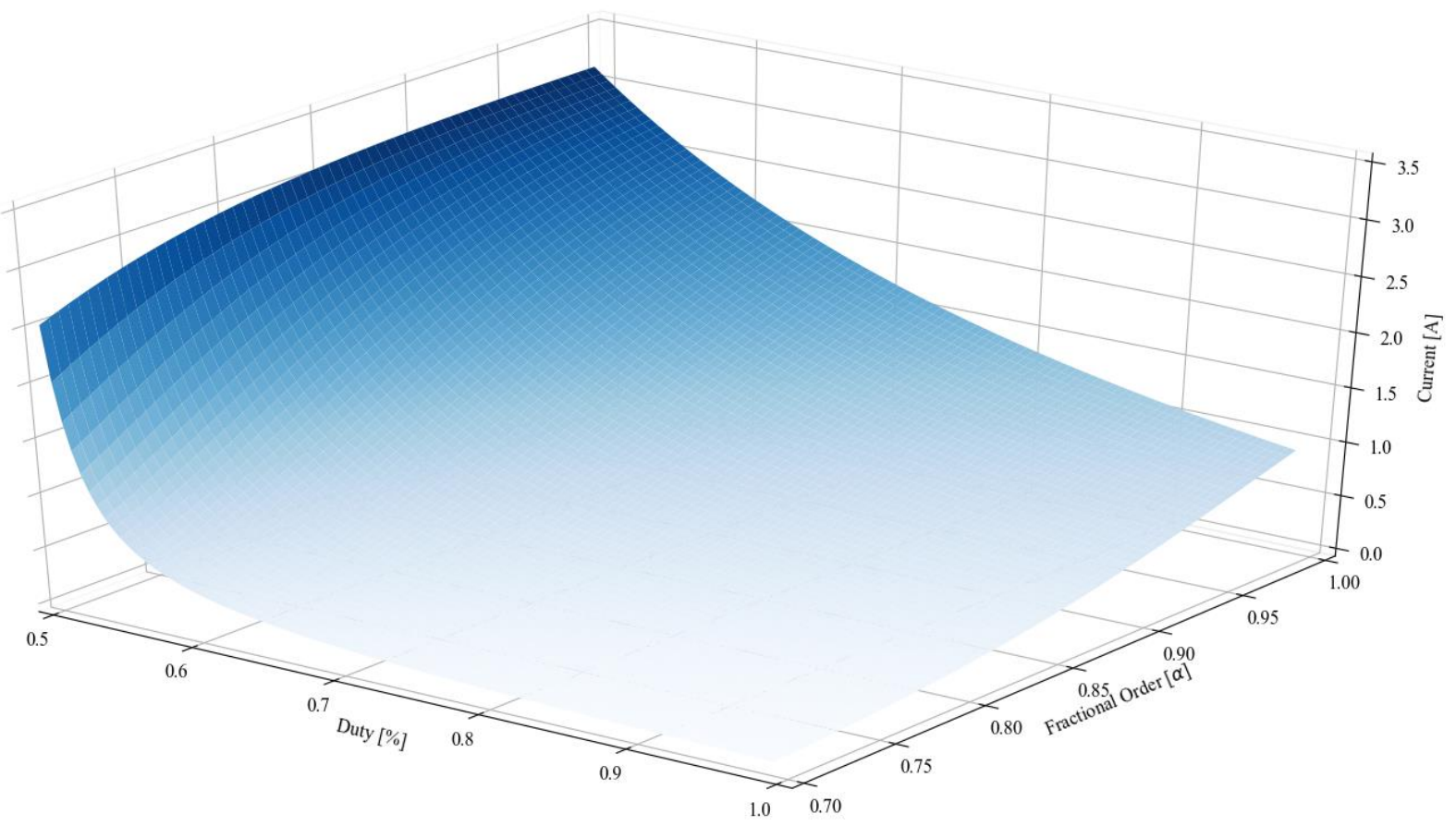

Fig. 5. Steady state for the current through the inductor $0.7<\alpha<1$ and $0.5<D<1$.

\section{CONCLUSIONS}

This paper presented a novel modelling approach for real DCDC converters with fractional capacitors. The main contribution of this paper consists on the analyses of the impact of fractional order over the time response of a Boost converter with fractional capacitor modelling with fractional derivatives including losses in the inductor and fractional capacitor.

The possibility of modelling real DC-DC converters with fractional capacitors using FDE allows the exploration of new applications of DC-DC converters. The results performed in this paper show that both voltage of the fractional capacitor and current of the inductor in a real Boost converter with a fractional capacitor changes in function of the fractional order $(\alpha)$, this holds even when the same circuital parameters $L, R$, $C$, switching frequency and duty are considered.

The results obtained for the Boost converter show that the fractional order $\alpha$ has a significant impact on the dynamic of the converter. However, several parameters such as voltage ripple, current ripple and steady state voltage are sensible to 
fractional order duty values $D<70 \%$. Several values of $\alpha$ were considered in the study with the purpose of evaluating the response of a Boost converter under the action of $\alpha$ close to 0.7 and close to 1 . Also, several common values of duty were considered $50 \%<D<100 \%$ with the purpose of showing the behaviour of Boost converters in function of duty and fractional order. The results show that moderate loses represented by $R_{C}$ and $R_{L}$ have an important impact over the dynamic of a Boost converter. Also, the fractional order has an important impact over the response of the Boost converter. This allows concluding that $\alpha$ is an alternative to modify the response of Boost converters allowing to control a DC converter with fractional capacitor with the duty and fractional order $\alpha$.

\section{ACKNOWLEDGMENT}

The authors gratefully acknowledge the financial support provided by the Colombia Scientific Program within the framework of the call Ecosistema Científico (Contract No. FP44842- 218-2018). Also, the authors want to acknowledge the "Proyecto de Sostenibilidad" of Universidad de Antioquia.

\section{REFERENCES}

[1] Chen, Xi, Yanfeng Chen, Bo Zhang, and Dongyuan Qiu (2017). A modeling and analysis method for fractional-order DC-DC converters. IEEE Transactions on Power Electronics 32 (9), 7034-7044. DOI: 10.1109/TPEL.2016.2628783

[2] Burke, A. (2000). Ultracapacitors: why, how, and where is the technology. Journal of power sources 91 (1), 37-50. DOI: 10.1016/S03787753(00)00485-7.

[3] Das, S. and N. Pramanik (2014). Indigenous development of carbon aerogel farad super-capacitors and application in electronics circuits. BARC News Letter Issue 1 (339), 1-6, 2014. DOI: 10.1023/A:1009629423578.

[4] Torreglosa, J. P., P. Garcia, L. M. Fernández, and F. Jurado (2014). Predictive control for the energy management of a fuel-cell-battery supercapacitor tramway. IEEE Transactions on Industrial Informatics 10(1), 276-285. DOI: 10.1109/TII.2013.2245140

[5] Thounthong, P., S. Rael, and B. Davat (2007). Control strategy of fuel cell and supercapacitors association for a distributed generation system. IEEE Transactions on Industrial Electronics 54(6), 3225-3233. DOI: 10.1109/TIE.2007.896477

[6] Radwan, A. G., Emira, A. A., AbdelAty, A. M., \& Azar, A. T. (2018). Modeling and analysis of fractional order DC-DC converter. ISA transactions, 82, 184-199. DOI: 10.1016/j.isatra.2017.06.024

[7] Zhao, X., Yin, Y., \& Zheng, X. (2016). State-dependent switching control of switched positive fractional-order systems. ISA transactions, 62, 103108. DOI: $10.1016 /$ j.isatra.2016.01.011

[8] Saichand, K. and V. John (2017). Simplified modeling of ultracapacitors for bidirectional $\mathrm{dc}-\mathrm{dc}$ converter applications. In Applied Power Electronics Conference and Exposition (APEC), 2017 IEEE, pp. 31343141. IEEE. DOI: 10.1109/APEC.2017.7931145

[9] Moayedi, S., F. Cingoz, and A. Davoudi (2013). Accelerated simulation of high-fidelity models of supercapacitors using waveform relaxation techniques. IEEE Transactions on Power Electronics 28(11), 4903-4909.

[10] Quintana, J., A. Ramos, and I. Nuez (2006). Identification of the fractional impedance of ultracapacitors. IFAC Proceedings Volumes 39(11), 432-436. DOI: 10.3182/20060719-3-PT-4902.00073

[11] Urrea-Quintero, J.-H., N. Munoz-Galeano, and L.-M. GomezEchavarria (2018). Analysis and control of power electronic converters based on a system zero locations approach. In Applied Modern Control. In Techopen. DOI: 10.5772/intechopen.80426

[12] Stankiewicz, A. (2017). Fractional order RLC circuits. In Electromagnetic Devices and Processes in Environment Protection with Seminar Applications of Superconductors (ELMECO \& AoS), 2017
International Conference on, pp.1-4. IEEE. DOI: 10.1109/ELMECO.2017.8267766

[13] Chen, Y., X. Ke, and Y. Wei (2015). Numerical algorithm to solve system of nonlinear fractional differential equations based on wavelets method and the error analysis. Applied Mathematics and Computation 251, 475-488. DOI: $10.1016 /$ j.amc.2014.11.079

[14] Almeida, R. and N. R. Bastos (2016). A numerical method to solve higher-order fractional differential equations. Mediterranean Journal of Mathematics 13(3), 1339-1352. DOI: 10.1007/s00009-015-0550-2

[15] Diethelm, K. (2010). The analysis of fractional differential equations: An application-oriented exposition using differential operators of Caputo type. Springer Science \& Business Media. ISBN 978-3-642-14574-2

[16] Kaczorek, T. and K. Rogowski (2015). Fractional linear systems and electrical circuits. Springer. ISBN 978-3-319-11361-6

David E. Betancur-Herrera received his B.Sc. and M.Sc degrees in Electric Engineering from the University of Antioquia in 2017 and 2020, respectively. Hi is a member of the Research Group GIMEL. His research work is focused in power electronics and mathematic applications in engineering. ORCID: https://orcid.org/0000-0003-2206-7292

Nicolás Muñoz-Galeano received his B. E. degree in Electric Engineering at the University of Antioquia (UdeA-2004), and the Ph.D. degree in Electronics Engineering (UPVLC-2011). Since 2005 he has been professor of the Electric Engineering Department at the University of Antioquia (Colombia) and member of research group GIMEL. His research work is focused in power electronics design, control and electrical machines.

ORCID: https://orcid.org/0000-0003-1407-5559

Juan B. Cano-Quintero received his B.Sc. degree in Electronics Engineering at the University of Antioquia (Colombia-2008) and PhD degree on Sensor and Learning Systems at Tor Vergata University (Italy2012). Since 2012 he is full-time professor at Electrical Engineering department at University of Antioquia. His research interests are power electronics, sensor systems and solar energy.

ORCID: http://orcid.org/0000-0003-4767-1007

Jesús M. López-Lezama received his B.Sc. and M.Sc. degrees from the Universidad Nacional de Colombia in 2001 and 2006, respectively. He also received his Ph.D. degree at the Universidade Estadual Paulista (UNESP), SP, Brazil in 2011. Currently he is an associate Professor at Universidad de Antioquia, Medellín, Colombia. His major research interests are planning and operation of electrical power systems and distributed generation.

ORCID: https://orcid.org/0000-0002-2369-6173 